\title{
UMA PROPOSTA DE INVESTIGAÇÃO HISTÓRICO-EPISTEMOLÓGICA SOBRE SEQUÊNCIAS RECORRENTES DE $2^{\mathrm{a}}$ ORDEM
}

\author{
Francisco Regis Vieira Alves \\ fregis@ifce.edu.br \\ https://orcid.org/0000-0003-3710-1561 \\ Instituto Federal de Educação, Ciências e Tecnologia do Estado do Ceará - IFCE. \\ Brasil \\ Paula Maria Machado Cruz Catarino \\ pcatarino23@gmail.com \\ https://orcid.org/0000-0001-6917-5093 \\ Universidade de Trás-os-Montes e Alto Douro \\ Portugal
}

Recibido: 2020-05-14; Aceptado: 2020-11-27

Resumo. A formação de professores no Brasil não pode prescindir de um componente históricomatemático e evolutivo. Nesse sentido, se torna imprescindível ao professor compreender a natureza intrinseca sobre o conhecimento matemático e seus processos ou itinerários de evolução e de irrefreável generalização. Dessa forma, o presente trabalho apresenta os dados preliminares de uma investigação amaparada pelos pressupostos de uma Engenharia Didática de Formação, em desenvolvimento no Brasil. O trabalho revela a uma importante cooperação científica envolvendo pesquisadores portugueses, sobre o asssunto de sequências recorrentes de $2^{\mathrm{a}}$ ordem e aponta a contribuição de pesquisas desenvolvidas no período de 2015 - 2020, no Programa de Pós-graduação em Ensino de Ciências e Matemátca, do Instituto Federal de Educação, Ciências e Tecnologia do Estado do Ceará - IFCE. Por fim, o trabalho apresenta algns indicadores que devem demarcar um importante cenário para a formação (inicial e continuada) de professores no Brasil.

Palavras-chave: História e Epistemologia da Matemática; Sequências recorrentes; Formação de Profesores de Matemática; Engenharia Didática de Formação.

\section{A PROPOSAL FOR HISTORICAL-EPISTEMOLOGICAL RESEARCH ON THE 2ND ORDER SEQUENCES}

\begin{abstract}
Teacher training in Brazil cannot do without a historical-mathematical and evolutionary component. In this sense, it is essential for the teacher to understand the intrinsic nature of mathematical knowledge and its processes or itineraries of evolution and irrepressible generalization. Thus, the present work presents the preliminary data of an investigation supported by the assumptions of Didactic Engineering of Training, under development in Brazil. The work reveals an important scientific cooperation involving Portuguese researchers, on the subject of recurrent 2 nd order sequences and points out the contribution of research developed in the period 2015 - 2020, in the Postgraduate Program in Science Teaching and Mathematics, of the Institute Federal Institute of Education, Science and Technology of the State of Ceará IFCE. Finally, the work presents some indicators that should outline an important scenario for the training (initial and continuing) of teachers in Brazil.

Keywords: History and Epistemology of Mathematics; Recurring strings; Mathematics Teacher Training; Didactic Engineering Training.
\end{abstract}




\section{Introdução}

A tradição dos compêndios de História da Matemática utilizados no Brasil costuma assinalar, de modo restritivo, um viés pitoresco, anedótico e episódico envolvendo um contexto de discussão à respeito de aspectos históricos do conbecimento matemático. Não obstante, se mostra imprescindível para o professor de Matemática adquirir uma compreensão dos estadio de gênese, da irrefreável evolução matemátoca e epistemológica, bem como da constante sistematização das ideias científicas, conceitos e objetos matemáticos, confirmados por parte de especialistas e matemáticos profissionais, tanto do passado, bem como, em nosso momento atual.

Com atenção especial, quando objetivamos o professor de Matemática e sua atividade docente no Brasil, urge a imprescindível constituição de um repertório de conhecimentos e saberes profissionais, capacitando-o à respeito de uma compreensão aprofundada sobre a História da Matemática, com maior ênfase nos conceitos mais próximos do contexto escolar, diferentemente do que deparamos nos livros de História da Matemática utilizados no Brasil, que costumam dedicar maior atenção e amplo exame sobre os fundamentos de Análise e Cálculo Diferencial e Integral (Alves, 2017). Apesar de que estes não costumam ser objetos de ensino explícito no contexto da Educação Básica e outros conteúdos se mostram presentes no sistema de ensino brasileiro.

Com origem panorama anterior, no presente trabalho trazemos uma proposta de estudo de sequências recorrentes lineareas de $2^{\mathrm{a}}$ ordem. De forma usual, deparamos alguma atenção dispensada ao caso da sequência de Fibonacci, cujo viés episódico, caráter figurativo e pitoresco costuma ser priorizado e discutido, em detrimento de expressar e comunicar ao professor de Matemática, um processo indene evolutivo e de generalização epistemológica de uma espécie de modelo matemático evolutivo para a Sequência Generalizada de Fibonacci.

Por outro lado, no presente trabalho, reportamos os dados mais representativos e preliminares sobre investigações desenvolvida a partir de uma cooperação científica envolvendo pesquisadores do Brasil e de Portugal e, ainda, trabalhos desenvolvidos por estudantes de um programa de pós-graduação em Ensino de Ciências e Matemática, do Instituto Federal de Educação, Ciência e Tecnologia do Estado do Ceará - IFCE, no perído 2015 - 2020. Nosso interesse envolve a concepção e a constituição sistemática de recursos pedagógicos e didáticos, 
visando a formação inicial de continuada de professores de Matemática no Brasil, sobre o tema: sequências numéricas recorrentes homogêneas de $2^{\mathrm{a}}$ ordem.

$\mathrm{Na}$ tabela 1 apresentamos alguns dados preliminares sobre dissertações envolvendo projetos de pesquisas finalizados e outros em desenvolvimento no ano de 2020.

Tabela 1. Dissertações envolvendo projetos desenvolvidos no Programa de Mestrado em Ensino de Ciências e Matemática - PGECM

\section{Título da Dissertação/ano}

Dos Santos (2017) - Uma Engenharia

Didática para a noção de sequência extendida de Fibonacci: uma experiência no contexto do IFCE.

Oliveira (2018) - Engenharia Didática com o tema: relações bidimensionais, tridimensionais e n-dimensionais do modelo de Fibonacci.

\section{Objeto de investigação}

A dissertação envolveu o desenvolvimento de uma pesquisa com o interesse no processo de generalização da Sequência de Fibonacci e a proposição de uma Engenharia Didática.

A dissertação envolveu o desenvolvimento de uma pesquisa com o interesse no processo ndimenssional de representação da Sequência de Fibonacci e a proposição de uma Engenharia Didática de Formação.

A dissertação envolveu o desenvolvimento de uma pesquisa com o interesse no processo de evolução e generalização da Sequência de Jacobsthal e a proposição de uma Engenharia Didática de Formação.

Guedes (2020) - Uma Engenharia Didática para o estudo da Sequência Generalizada de Lucas (SGL).
A dissertação envolveu o desenvolvimento de uma pesquisa com o interesse no processo de evolução e generalização da Sequência de Lucas e a proposição de uma Engenharia Didática de Formação.

\section{Total de dissertações} Investigação e Formação

$\mathrm{Na}$ tabela 1 acima, indicamos alguns dos trabalhos realizados, todavia, visando a descrição de um itienerário investigativo sistemático, na seção subsequente, indicaremos os pressupostos assumidos em nossa proposta que, com o amparo da noção de uma Engenharia Didática de Formação (EDF) e de determinados elementos oriundos da Teoria das Situações (Brousseau, 1997), possibilita objetivarmos o acúmulo de conhecimentos, concepção de dispositivos que incidem e repercutem na formação (inicial ou continuada) de professores no Brasil. Por conseguinte, adoção dos elementos de natureza de um design de investigação, recorrentemente empregado no campo da didática da Matemática, garantirá nossa sistemática de pesquisa e do rigor necessário para o desenvolvimento da pesquisa.

\section{Sobre o design de investigação}


No Brasil, registramos uma considerável influência da vertente francesa da Didática da Matemática (DM). Tal vertente, cuja consolidação científica e reconhecimento internacional ocorrido pelo final dos anos 80, repercutiu e, também, influenciou o desenvolvimento e consolidação de uma profusão de investigações no Brasil, sobretudo, nos últimos 20 anos.

De modo tradicional, a (DM) emprega uma perspectiva multeórica visando a compreensão dos fenômenos derivados da interação dos elementos do trinômio clássico indicado por estudante - professor - saber matemático (Artigue, 1991; 2002). Por outro lado, assumimos uma perspectiva influenciada pela reorientação dos interesse e pressupostos assumidos no interior da (DM), sobretudo, quando obvetivamos os fundamentos da noção de Engenharia Didática, subdividida em Engenharia Didática Clássica ou de $1^{\mathrm{a}}$ geração e Engenharia Didática de $2^{\mathrm{a}}$ geração ou, nomeada, também, por Engenharia Didática de Formação. No trecho abaixo, apesar de extenso, revela maior interesse pela formação e, acrescentamos, pela necessidade de compreensão dos fenômenos derivados da atividade do professor de Matemática desenvolvida no trabalho, com origem no contexto educacional francês, a partir dos anos 90 (Perrin - Glorian, 2011).

Na própria França, outros marcos teóricos se desenvolveram entre o final da década de 1970 e o início da década de 1980, cujo trabalho de fundação se baseou na engenharia didática como metodologia de pesquisa, com prolongada engenharia e monitoramento de classe, ao longo de vários anos. É o caso da dialética da ferramenta objeto e do conjunto de quadros desenvolvido por Régine Douady. A teoria dos campos conceituais, apesar de ter um ponto de partida diferente, também foi nutrida pelo trabalho de engenharia didática, notadamente em proporcionalidade e volume na década de 1980, depois em outros conteúdos [...] A partir da década de 1990, o leque de questões abordadas pela didática e pela Engenharia Didática ampliou-se, em particular, ao estudo do papel do professor e à formação de professores e a questões mais transversais, como uso de novas tecnologias. (PerrinGlorian \& Bellemain, 2019, p. 51-52).

Como bem observamos, por intermédio de um processo evolutivo próprio e característico da evolução da área de investigação, observamos duas categorias de interesses de Engenharias Didáticas. A primeira categoria, denominada Engenharia Didática de $1^{a}$ geração ou clássica e a segunda, denominada de Engenharia Didática de $2^{\mathrm{a}}$ geração. Cabe observar, entretanto, que no seu contexto de origem, a tradição dos estudos envolvendo o emprego dos pressupostos de uma Engenharia Didática costumavam enfatizar maior interesse pela 
aprendizagem do estudante, entretanto, o próprio interesse dos especialistas da área em disseminar e acumular conhecimentos científicos sobre os fenômenos derivados do ensino e da aprendizagem, compreenderam, a proximadamente ao final dos anos 90, que o papel do professor de Matemática requer maior atenção e desenvolvimento de pesquisa sobre o assunto (Artigue, 1988; 1991; 2002; Perrin-Glorian \& Bellemain, 2020). No trecho seguinte deparamos a explicação de Artigue (2002) envolvendo determinada mudança de interesses.

Mesmo que tenha sido formada na França, adotando uma abordagem sistêmica, a didática da matemática, no início, concentrou seus esforços na disciplina de aprendizado e em suas interações com o conhecimento. O professor, parceiro do pesquisador no desenho e experimentação da engenharia didática ou potencial usuário dos resultados da pesquisa, permanece uma figura transparente, pouco questionada. No final da década de 1980, no entanto, as limitações induzidas por esse ponto de vista eram cada vez mais sentidas e a necessidade de considerar o professor como um ator pleno na situação didática, tão imprevisível e previsível quanto a aluno em seu comportamento, se impõe à comunidade de pesquisa. (Artigue, 2002, p. 66)

De modo tradicional, a Engenharia Didática prevê o desenvolvimento sistemático da fases de: (i) análises preliminares, (ii) análise a priori; (iii) experimentação; (iv) análise $a$ posteriori. De modo simplificado, na etapa (i) realizamos um levantamento e um exame do ensino atual, sobre determinado assunto ou conteúdo matemático (em nosso caso sequências numéricas recorrentes), incluindo a demarcação do campo matemático, epistêmico e histórico de interesse. A etapa (ii) consiste no desenvolvimento e análise a priori de uma série de situações didáticas estruturadas, de acordo com as hipóteses resultantes dos estudos preliminares e alcançáveis com os alunos do nível especificado e balizadas por intermédio da Teoria das Situações Didáticas (TSD) (Brousseau, 1997).

Todavia, em nosso caso, desde que consideramos professores em formação, se mostra importante considerar nas análises preliminares, as ponderações de Perrin-Glorian \& Bellemain (2019) ao comentarem que:

As análises preliminares se referem aos estudos epistemológicos, cognitivos e institucionais necessários para o desenvolvimento de uma série de situações a serem vivenciadas em sala de aula. Eles podem consistir em estudos originais, mas em qualquer caso incluem um estudo bibliográfico sobre a questão que é o objeto da pesquisa. (Perrin-Glorian \& Bellemain, 2019, p. 59). 
Na figura abaixo indicamos um itinerário de investigação realizado na investigação de Barquero \& Bosch (2015). Observamos, porém, que os autores desenvolveram uma Engenharia Didática de Formação e, determinadas modificações e a natureza das relações são consideradas, na medida em que, ocorre interesse maior pelos fenômenos derivados da aprendizagem do adulto e, neste caso, do professor de Matemática.

Dessa forma, podemos observar que, a despeito do itinerário das fases da Engenharia seguir as quatro etapas clássicas indicadas há pouco, recordamos a perspectiva assinalada por Tempier \& Chambris (2017) quando recordam que a noção de Engenharia retomada por PerrinGlorian (2011) possui interesse na formação, na constituição de recursos para o professor e sua divulgação e, em tal design de investigação, “o desenvolvimento de recursos para o ensino constitui um dos objetivos da investigação" (Tempier \& Chambris, 2017, p. 5). Assim, na figura 2 abaixo, divisamos outros elementos contemplados por nossa Engenharia de Formação.

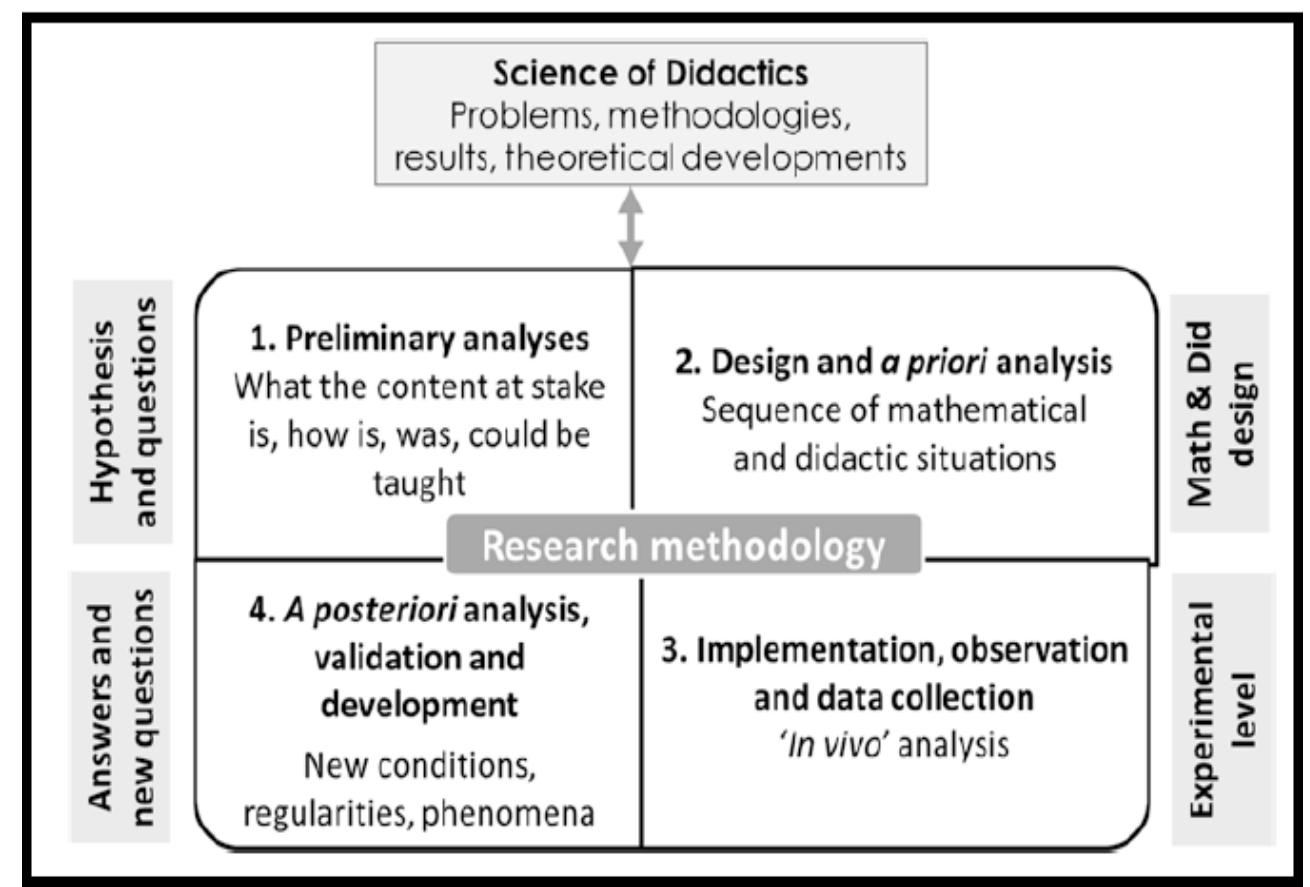

Figura 1. Desenvolvimento de uma Engenharia Didática segundo Barquero \& Bosch (2015) 


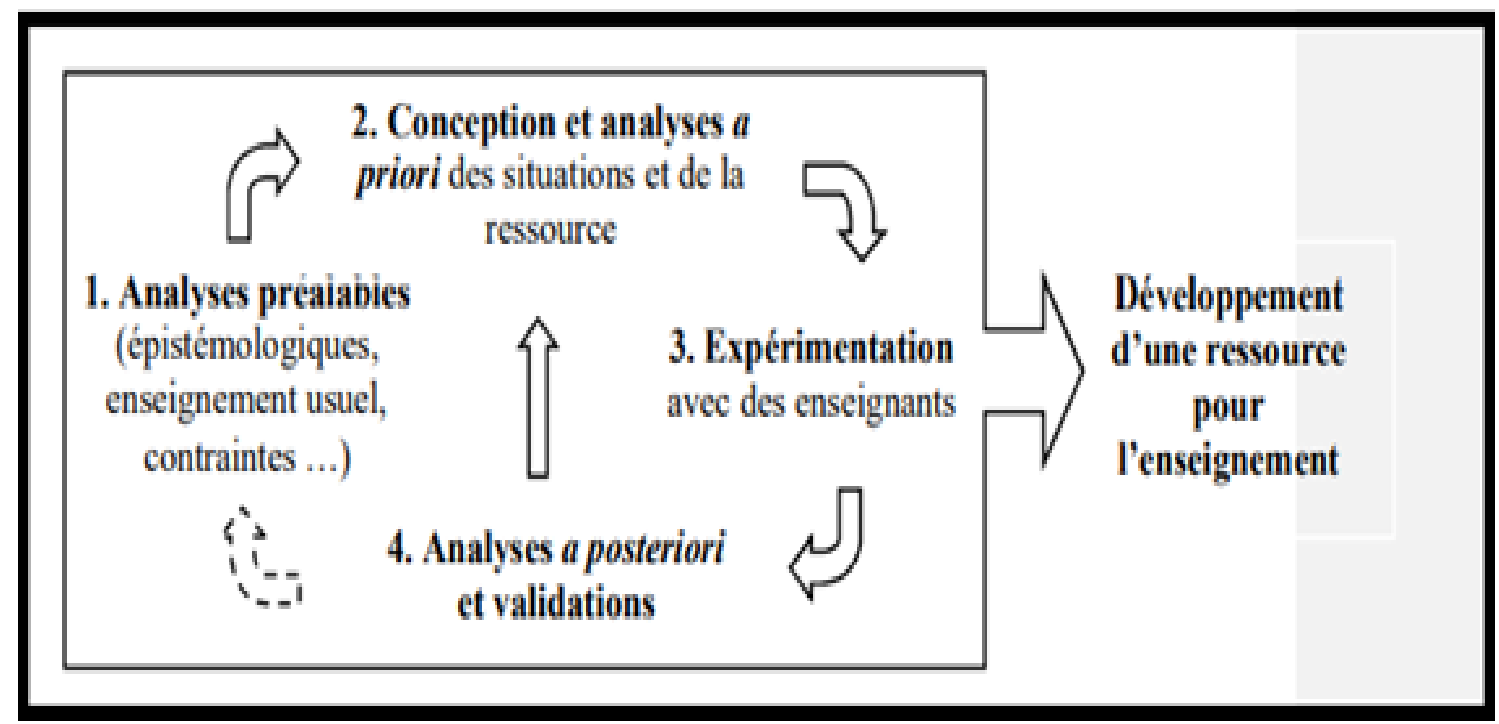

Figura 2. Engenharia Didática de Formação proposto por Tempier \& Chambris (2017)

Na figura 2 acima, divisamos o esquema proposto por Tempier \& Chambris (2017). Reparempos que, um dos produtos de uma Engenharia de Formação reside na constituição de um recurso para a formação de professores. Podemos identificar que, na etapa de esperimentação (expérimentation), a participação do professores se mostra um fato fundamental, tendo em vista a concepção e ajuste de situações didáticas e um desenvolvimento satisfatório de determinadas transposições didáticas, tomando como referência um assunto objetivado. Nas seções subsequentes, indicaremos alguns dados mais representativos de nosso estudo, considerando o período 2017 - 2020, que desenvolvemos no Brasil.

\section{Cooperação e pesquisa Brasil x Portugal}

Registramos a intensa produção de trabalhos em periódicos científicos que revelam os traços essenciais não apenas matemáticos mas, também, epistemológicos e evolutivos de determinadas classes de sequências recorrentes. Por outro lado, não podemos desconsiderar o caráter cifrado e demasiadamente restritivo de uma cultura matemática peculiarmente comunicada pelos periódicos e jornais especializados internacionais (Campos et all, 2014; Catarino, 2016; 2019; Catarino \& Vasco, 2013; Catarino \& Borges, 2020; Catarino; Campos \& Vasco, 2019).

Dessa forma, com maior atenção aos trabalhos originados de investigações desenvolvidas em Portugal, no âmbito da Matemática Pura, optamos por desenvolver um processo de transposição científica e transposição didática, capaz de aproximar e de proporcionar ao professor, em formação inicial e continuada no Brasil, uma maior compreensão 
sobre um proesso histórico, matemático e, sobretudo, com teor evolutivo atinente ao conceito matemático-científico de sequências numéricas e recorrentes.

Após realizar um extenso levantamento bibliográfico com a consulta de livros de História da Matemática e de artigos especializados sobre o assunto, registramos um conjunto de dez sequências recorrentes de $2^{\mathrm{a}}$ ordem. A partir desse exame preliminar, constatamos que os livros de História da Matemática adotados no Brasil costumam enfatizar a abordar, predominantemente as sequências de Fibonacci e de Lucas e, em poucos casos, deparamos a discussão de ementos relacionados com a sequência de Pell.

Ademais, relativamente ao conjunto complementar das sete sequências numéricas restantes, que podemos observar na tabela 2, observamos a quase e total omissão dos autores, diante de uma abordagem de suas propriedades e generalizações. Por outro lado, o processo de matemático-epistemológicogeneralização do modelo de recorrência e o estádio atual de interesse por parte de especialistas é desconsiderado, proporcionando uma visão estática e não evolutiva do conhecimento matemático em questão, sobretudo, quando objetivamos professsores de Matemática em formação (inicial ou continuada).

Tabela 2. Descrição e levantamento blibliográfico da sequências recorrentes de $2^{\mathrm{a}}$ ordem

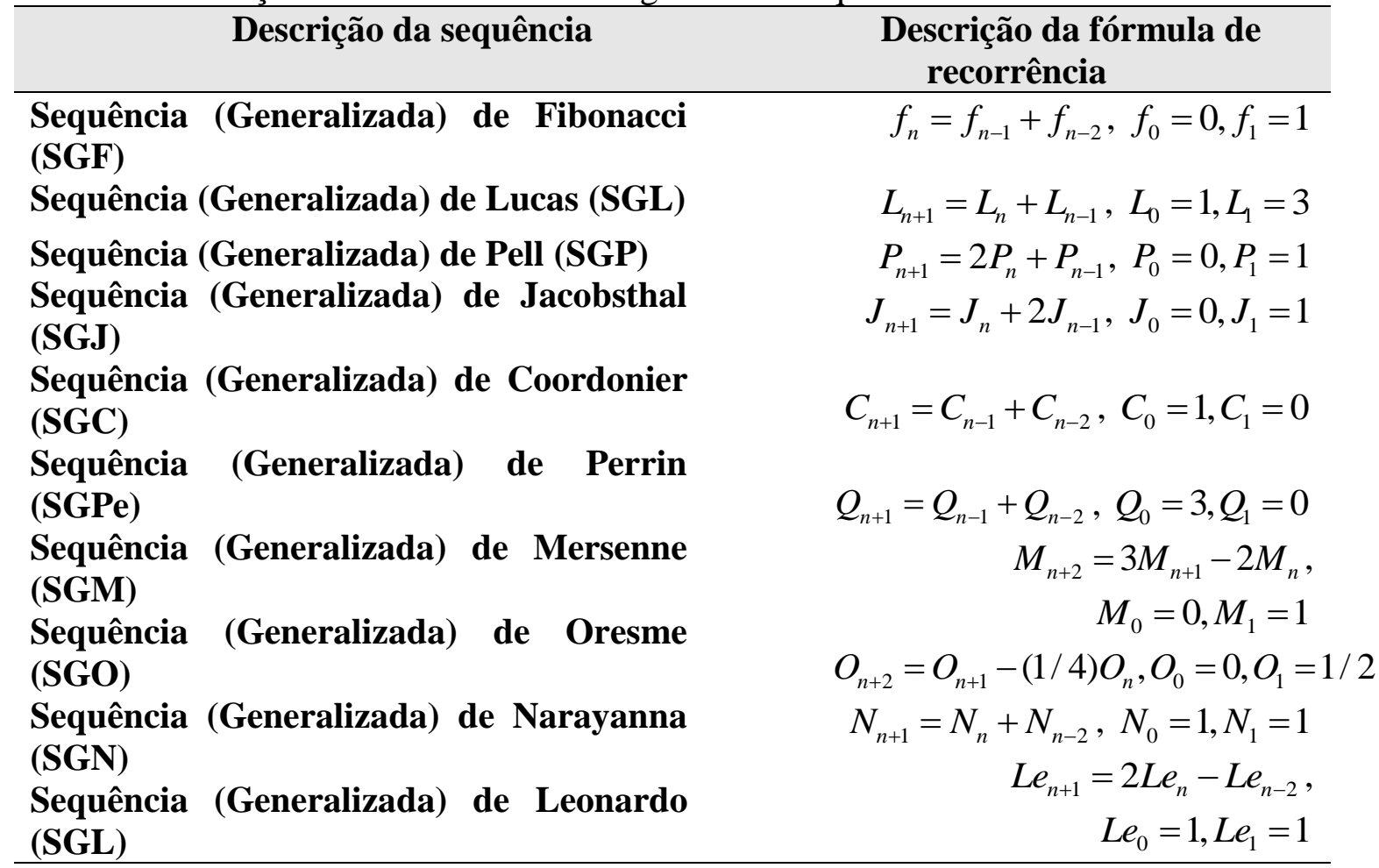

Total considerado na pesquisa Dez sequências recorrentes

Fonte: Elaboração dos autores. 
Com origem nos dados apontados há pouco, definimos alguns assuntos abordados em determinados periódicos especializados de Matemática Pura, visando a transposição didática (Chevallard, 1991) correspondente, aproximando-os da realidade e da compreensão dos professores que atuam na Educação Básica no Brasil.

Dentre os assuntos ou abordagens escolhidas, destacamos: (i) propriedades e representação matricial de sequências recorrentes; (ii) descrição do processo de extensão para índices no campo dos inteiros; (iii) descrição de funções relacionadas com a generalização das sequências; (iv) estudo de recorrência n-dimensional; (v) introdução de unidades imaginárias $i, j, k$, duais, hiperbólicas, etc; (vi) descrição de representação com unidade híbridas ou números híbridos; (v) decrição do modelo computacional (2D/3D) e a visualização do modelo fratal relacionado com determinadas sequências numéricas, com o emprego de softwares, tais como: Cas Maple, GeoGebra, Maxima, etc.

Não desenvolvermos maiores detalhes sobre os itens indicados acima e outras informações podem ser consultadas em trabalhos derivados da cooperação científica Brasil x Portugal (Alves \& Vieira, 2020). Entretanto, merecem destaque determinadas propriedades e definições matemáticas introduzidas recentemente na literatura científica.

Por exemplo, no trabalho recente de Alves (2019a), deparamos um exame minucioso de propriedades e a descrição de novas definições relacionadas com a (SGO). Por exemplo, Alves (2019) comenta a propriedade da extensão ao campo dos inteiros da (SGO), dada por $O_{n}=\left\{n \cdot\left(1 / 2^{n}\right), n \geq 0 ;-n \cdot\left(2^{n}\right), n<0\right.$. Em seguida, o autor comenta o trabalho de Cook (2004) que introduz uma nova noção de k-Sequência de Oresme, como uma generalização da (SGO) anterior. $\mathrm{O}$ autor introduziu a seguinte recorrência que indicamos por: $O_{k, n+2}=O_{k, n+1}-\left(1 / k^{2}\right) \cdot O_{k, n}, O_{k, 0}=0 ; O_{k, 1}=1 / k$, para todo $k \geq 2$. (Cook, 2004).

As representações matriciais relacionadas com os números de Fibonacci e de Jacobshtal, por exemplo, são consideravelmente já discutidas na literatura científica e são caracterizadas pelas matrizes de ordem $2 \times 2$, como indicamos a seguir. A determinação de potências dessas matrizes permitem determinar qualquer número presente na sequência numérica, a depender da ordem ou da potência da matriz escolhida (ver figura 3). 


$$
\begin{gathered}
M_{S F}=\left[\begin{array}{ll}
1 & 1 \\
1 & 0
\end{array}\right]^{n}=\left[\begin{array}{cc}
f_{n+1} & f_{n} \\
f_{n} & f_{n-1}
\end{array}\right], n \geq 1 \quad M_{S J}=\left[\begin{array}{cc}
1 & 2 \\
1 & 0
\end{array}\right]^{n}=\left[\begin{array}{cc}
J_{n+1} & 2 \cdot J_{n} \\
J_{n} & 2 \cdot J_{n-1}
\end{array}\right], n \geq 1 \\
M_{S L e}=\left[\begin{array}{lll}
3 & 1 & 1
\end{array}\right]\left[\begin{array}{ccc}
2 & 1 & 1 \\
0 & 0 & 1 \\
-1 & 0 & 0
\end{array}\right]^{n}=\left[\begin{array}{lll}
L e_{n+2} & L e_{n+1} & L e_{n}
\end{array}\right], n \geq 1
\end{gathered}
$$

Figura 3. Representaçõe matriciais relacionadas com as sequências de Jacobsthal, Fibonacci e Leonardo.

A sequência de Leonardo foi recentemente introduzida na literatura científica por pesquisadores porrtugueses (Catarino \& Borges, 2020). Os autores definiram a seguinte relação de recorrência $L e_{n}=L e_{n-1}+L e_{n-2}+1, n \geq 2, L e_{0}=1, L e_{1}=1$. A partir desta relação de recorrência não homogênea avaliam o comportamento da expressão $L e_{n+1}-L e_{n}$ afim de verificar a relação de recorrência final que indicamos na tabela 2. Cabe observar que os autores portugueses não determinaram relações matriciais. Neste caso, podemos considerar a relação de extensão ao campo de índices inteiros, descrita pela recorrência $L e_{-n}=-L e_{-n+1}+L e_{-n+2}-1, n<2$. Vejamos alguns exemplos numéricos na figura 4. Propriedades semelhante pode ser encontrada em outro trabalho sobre a Sequência Generalizada de Oresme (Alves, 2019b).

\begin{tabular}{|c|c|c|c|c|c|c|c|c|c|}
\hline$L e_{-1}$ & $L e_{-2}$ & $L e_{-3}$ & $L e_{-4}$ & $L e_{-5}$ & $L e_{-6}$ & $L e_{-7}$ & $L e_{-8}$ & $L e_{-9}$ & $L e_{-10}$ \\
\hline-1 & 1 & -3 & 3 & -7 & 9 & -17 & 25 & -43 & 67 \\
\hline
\end{tabular}

Figura 4. Extensão da sequência de Leonardo (Le) ao campo de índices inteiros

Por sua vez, cada vez mais, registramos a interface da Matemática com a tecnologia. Desse modo, podemos mencionar alguns trabalhos que permitem visualizar determinadas propriedades geométricas, via fractais, derivados diretamente de sequências recorrentes. Para exemplificar, na figura 4 , visualizamos alguns fractais 2D relacionados com sequências. 


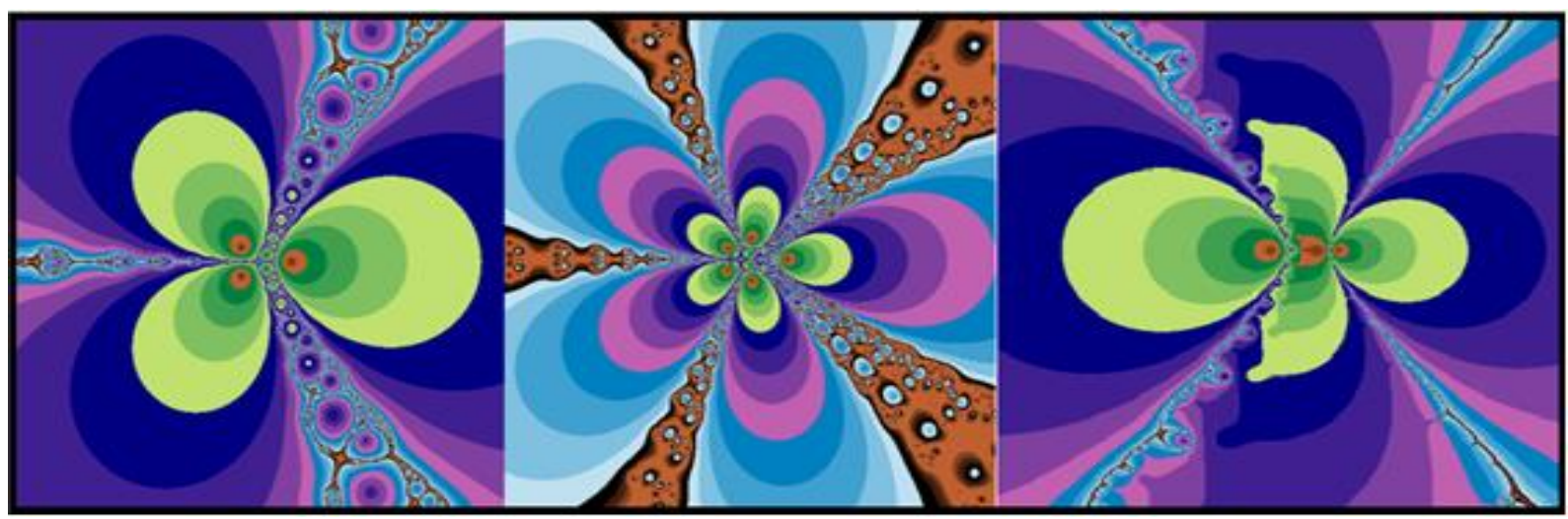

Figura 5. Exemplos de fractais 2D relacionados com as sequências de Mersenne e de Leonardo.

Registramos em nossos trabalhos (Alves; Catarino \& Mangueira, 2019; Alves \& Vieira, 2020) uma abordagem que acentua a importância da visualização, mediante representações fractais relacionadas com as sequências de Mersenne e de Leonardo. Na figura 5 exibimos apenas exemplos de fractais $2 \mathrm{D}$, possibilitadas por intermédio de recurso computacional. $\mathrm{Na}$ figura 6, Barros et all (2020) discutem a reprensentação de números híbridos.

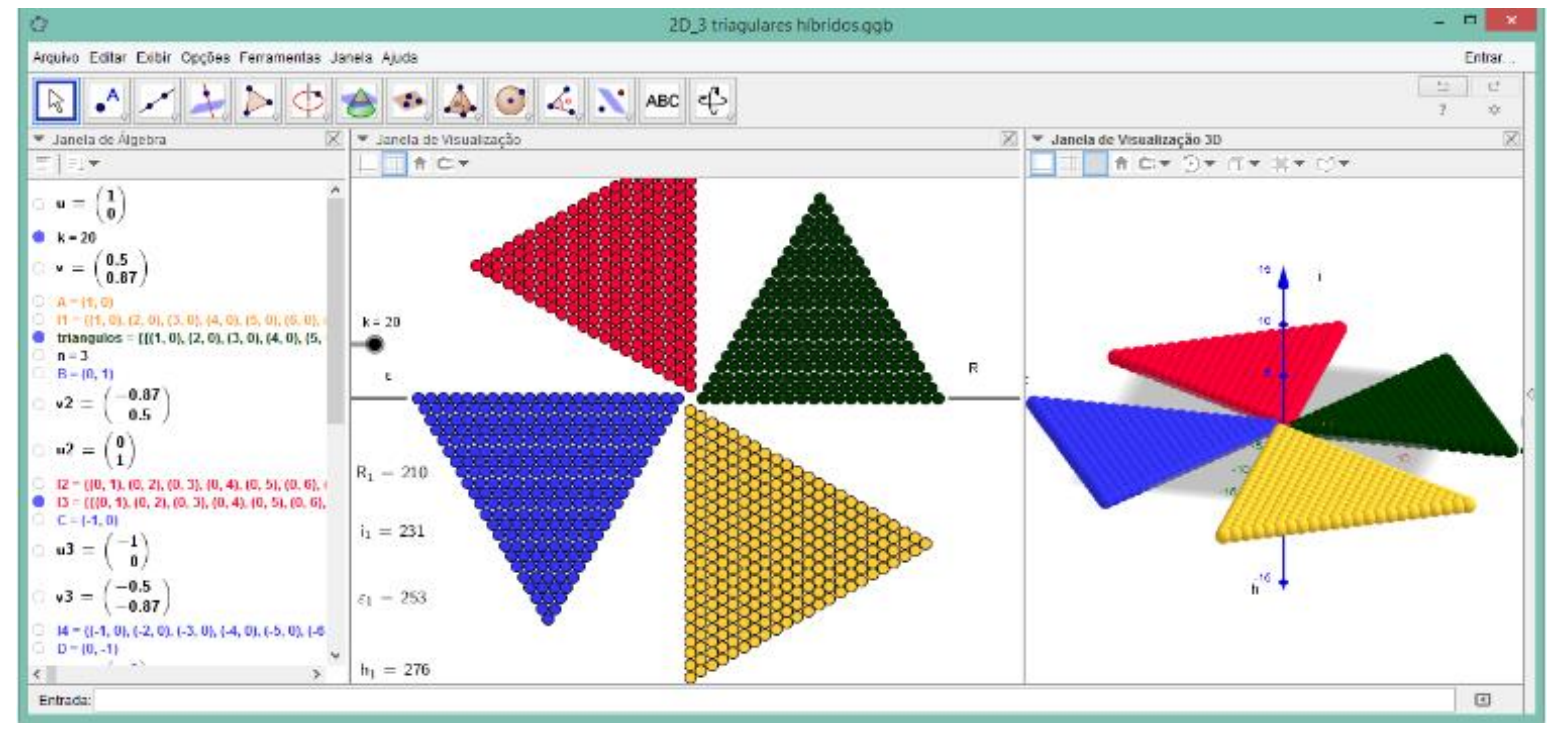

Figura 6. Barros et all (2020) discutem representações de números híbridos triangulas com o uso do software GeoGebra.

\section{Análises preliminares: estudo histórico - epistemológico das sequências recorrentes}

A dimenssão histórica e epistemológica possui grande importância para um estudo amparado pelos pressupostos de uma Engenharia Didática (Artigue, 1990). Em nosso caso, podemos examinar todo um processo constitutivo evolutivo de determinadas sequências numéricas recorrentes, bastando examinar o progresso de trabalhos publicados sobre o assunto, sobretudo ao decurso dos anos 60. (Gould, 1981; Stakov, 2009). 
Como temos registrado em nossos trabalhos, os componentes de História da Matemática não podem se limitar em transmitir ao professor de Matemática fragmentos episódicos, que desconsideram uma perspectiva epistemológica evolutiva de determinadas noções matemáticas, desde sua gênese até o interesse atual, por parte de matemáticos em todo o mundo. Respeitando os limites de apresentação deste trabalho, podemos recordar o trabalho de Harman (1981) que introduz a discussão sobre a representação complexa dos números de Fibonacci. Como decorrência de sua abordagem, deparamos um método de introdução de unidades imaginárias e a relação de recorrência bidimensional e tridimensional para Fibonacci. Maiores detalhes, sugerimos ao leitor consultar Harman (1981).

De um ponto de vista histórico evolutivo, podemos identificar alguns trabalhos que envolvem a generalização das ideias de Harman (1981). Como por exemplo, Iver (1961) que introduziu, pela primeira vez, a noção de n-ésimo Quaternion de Fibonacci, como um número $Q_{n}=f_{n}+f_{n-1} i+f_{n-2} j+f_{n-3} k$, em que $i, j, k$ representam as unidades imaginárias e gozam das propriedades. Na figura 7, Oliveira (2018) desenvolveu um exame do processo matemático, epistemológico evolutivo à respeito da Sequência Generalizada de Fibonacci. Oliveira (2018) constatou algumas tendências de estudos e publicações científicas que adotam o modelo de representações polinomiais, representações complexas e por meio de hipercomplexos (quaternions, octônions, sedênions, etc). (Oliveira \& Alves, 2019).

De forma semelhante, podemos exemplificar alguns elementos de ordem histórica sobre a sequência de Padovan ou de Coordonier (Shannon, A.G., Anderson, P.G. \& Horadam, 2006). Por outro lado, determinadas representações matriciais são registradas em literatura científica recente, o que confirma os traços evolutivos e de generalização matemática de um modelo de recorrência. Maiores detalhes, recomendamos consultar os trabalhos de Vieira \& Alves (2019a; 2019b) e de Vieira; Alves \& Catarino (2019). 


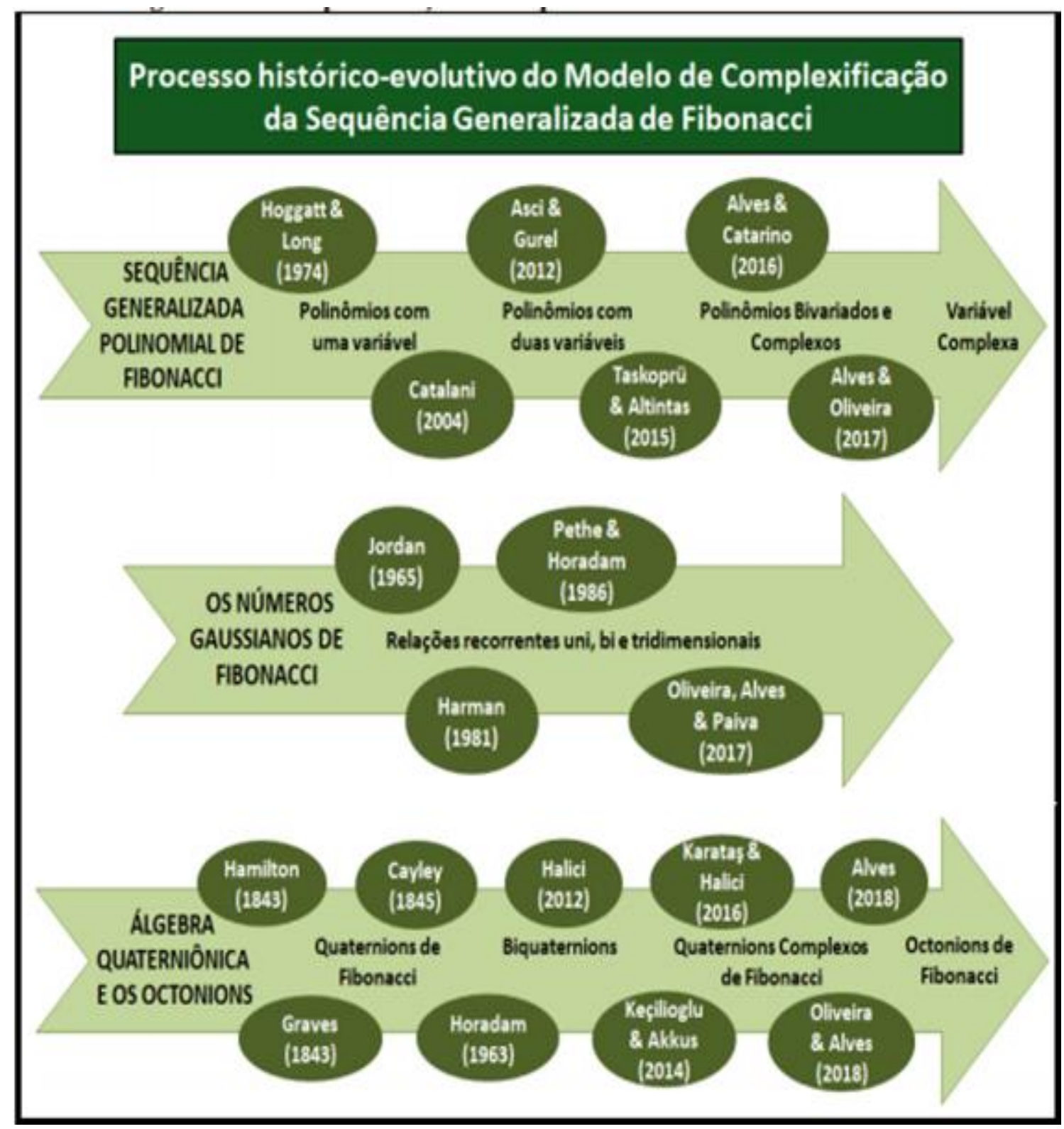

Figura 7. Oliveira (2018) discute um processo epistêmico-matemático evolutivo da Sequência Generalizada de Fibonacci (SGF)

Nosso último exemplo refere-se ao cenário cultural da Matemática indiana. De modo geral, a matemática indiana costuma não possuir espaço representativo de discussão nos compêndios especializados de História da Matemática adotados no Brasil (Alves, 2019b; 2020). Por outro lado, recordamos o problema do nascimento de novelhos, por intermédio de uma descrição de sequência recorrente e que, de certa forma, corresponde ao problema correlato do nascimento de coellhos popularizado por Leonardo Pisano. 
Em um outro contexto histórico e cultural, depara a sequência de Narayanna, que indicamos pela recorrência na tabela 2. Vários indícios apontam que determinadas idéais matemáticas conhecidas pelos indianos foram resgadas muito tempo depois, no século XIII, por exemplo, por Leonardo Pisano (Sridharan, R. ; Sridharan; R. \& Srinivas, 2015; Singh, 1985). Dentre eles, assinalamos a contribuição do matemático indiano Narayanna Pandita (1325 1400)Antes de finalizarmos a seção, podemos registrar que o trabalho do matemático francês François Olivier Raoul Perrin $(1841$ - 1910) foi o responsável pela introdução das ideáis relacionadas com a sequência que recebeu seu nome (ver tabela 1). No trabalho de Yilmaz \& Taskara (2013) encontramos a descrição de relações recorrentes matriciais. Neste sentido, podemos identificar uma tendência semelhante investigada por outros matemáticos e encontrada em publicações de periódicos, o que confirma um ininterrupto processo matemático evolutivo que, quando demarcamos com o origem da contribuição de Fibonacci, se revela, até nossos dias, preservando o interesse vigoroso na pesquisa.

\section{Análise a priori: concepção e descrição de um recurso para a formação de professores de Matemática no Brasil}

Nas seções predecessoras indicamos alguns elementos assumidos pelo nosso design de investigação em desenvolvimento no Brasil e com representativa influência da pesquisa desenvolvida em Portugal, por matemáticos profissionais. Na presente seção, acentuaremos os princípios de ordem metodológica e que favorecem e permitem aproximar, divulgar e repercutir uma cultura matemática sobre o conjunto das sequências que indicamos no quadro 1. Assumimos em ambas os pressupostos da Teoria das Situações Didáticas (Tempier, 2016) empregada para a formação de professores (Alves \& Catarino, 2019).

Situação Didática 1: No trabalho de Yilmaz \& Taskara (2013) deparamos a introdução, pela primeira vez, da relação recorrente de Padovan ou de Coordonier, em sua forma matriciai. Os autores definem, a partir da relação $\wp_{n+3}=\wp_{n+1}+\wp_{n}$, e os seguintes termos iniciais (ver figura 8): 


$$
\wp_{0}=\left(\begin{array}{lll}
1 & 0 & 0 \\
0 & 1 & 0 \\
0 & 0 & 1
\end{array}\right), \wp_{1}=\left(\begin{array}{lll}
0 & 1 & 0 \\
0 & 0 & 1 \\
1 & 1 & 0
\end{array}\right), \wp_{2}=\left(\begin{array}{lll}
0 & 0 & 1 \\
1 & 1 & 0 \\
0 & 1 & 1
\end{array}\right), n \geq 0
$$

Figura 8. Yilmaz \& Taskara (2013) descrevem elementos de uma sequência matricial recorrente

Com origem na formulação acima, determinar os elementos do tipo $\wp_{-n}$, com $n \geq 0$ e relacioná-los com as inversas das matrizes acima e a determinação dos elementos $C_{-n}$.

Situação Didática 2: Gould (1981) descreve um cenário de interesse pela pesquisa envolvendo emprego de métodos da Álgebra Linear visando a generalização de determinadas noções atinentes ao conceito de sequência recorrente. Nesse sentido, Gould (1981) recorda que a fórmula dada por Robert Simson em 1753, denominada identidade de Giovanni Domenico Cassini (1625 - 1712), pode ser indicada por $f_{n+1} f_{n-1}-f_{n}^{2}=(-1)^{n}$. Com origem nas representações matriciais abaixo, mostre fórmula semelhantes para as sequências de Oresme, Mersenne e de Jacobsthal (Ver figura 9).

$$
M_{\text {Oresme }}=\left(\begin{array}{cc}
2 \cdot O_{n+1} & -(1 / 2) \cdot O_{n} \\
2 \cdot O_{n} & -(1 / 2) \cdot O_{n-1}
\end{array}\right), M_{\text {Mersense }}=\left(\begin{array}{cc}
-2 \cdot M_{n-1} & M_{n} \\
-2 \cdot M_{n} & M_{n+1}
\end{array}\right), M_{\text {Jacobshal }}=\left[\begin{array}{cc}
J_{n+1} & 2 \cdot J_{n} \\
J_{n} & 2 \cdot J_{n-1}
\end{array}\right], n \geq 1
$$

Figura 9. Representações matriciais derivadas das sequências de Oresme, Mersenne e Jacobsthal

Na seção subsequente indicaremos alguns resultados e exemplos de dados coligidos a partir da aplicação e intervenção em sala de aula, visando a mobilização de conhecimentos dos professores atinentes aos conteúdos de sequências recorrentes.

\section{Análise a posteriori: alguns exemplos e resultados}

$\mathrm{Na}$ presente seção indicaremos alguns resultados que representam um acúmulo conhecimentos e a disseminação necessária de uma cultura matemática sobre a noção de 
sequência recorrente. Assumimos procedimentos de investigação semelhante ao de Tempier (2016) na implementação de situações didáticas com os professores e, segundo cada dissertação analisada, acentuaremos os elementos mais representativos. Não obstante, sobre as diculdades manifestas no itinerário de proposição de situações didáticas para professores, Tempier (2016) adverte que:

As discussões com os professores mostram primeiro que os professores têm dificuldades em escolher números possíveis (apenas um exemplo é fornecido no recurso). Alguns professores relataram ter dificuldade em implementar essa tarefa porque tinham medo de não encontrar números adequados. Na verdade, observei erros em uma das seleções possíveis de professores, o que impedia que ele colocasse em prática o conhecimento almejado. Essa complexidade revela que essa situação não é facilmente utilizável, o que leva os professores a seguir 'passo a passo' o que é proposto no recurso. (Tempier, 2016, p. 269).

Nas figuras 10 e 11 apresentamos a atividade de professores no estudo das (SGL) e (SGJ) e a descrição de sua representação polinômial, como apreciamos em Guedes (2020). Na figura 10 os professores em formação descobrem propriedades derivadas de representações matriciais derivadas da sequência de Jacobsthal. Diferentemente do estudo de Tempier (2016), que considerou um conjunto de professores experientes (experts), em nosso caso, consideramos amostras de professores inexperientes, tomados como amostra dos trabalhos que indicamos na tabela 1 .

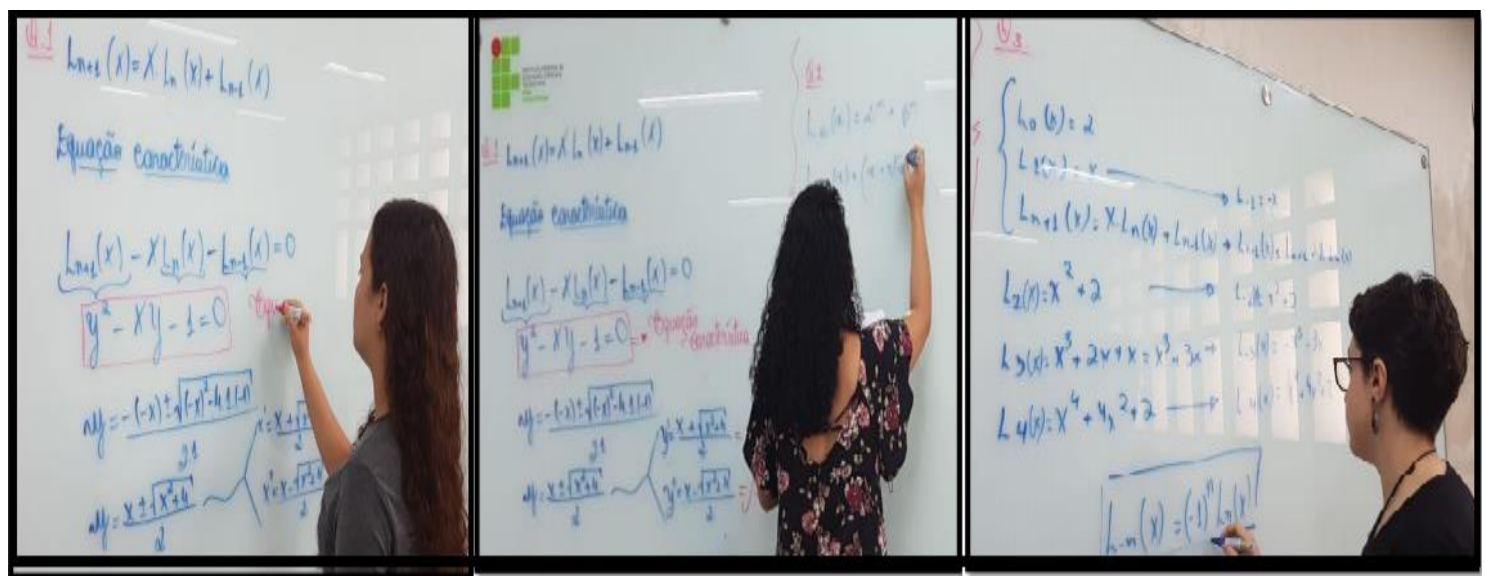

Figura 10. No estudo de Guedes (2020) deparamos a atividade de professores relacionadas com a Sequência Generalizada de Lucas em sua forma polinomial 


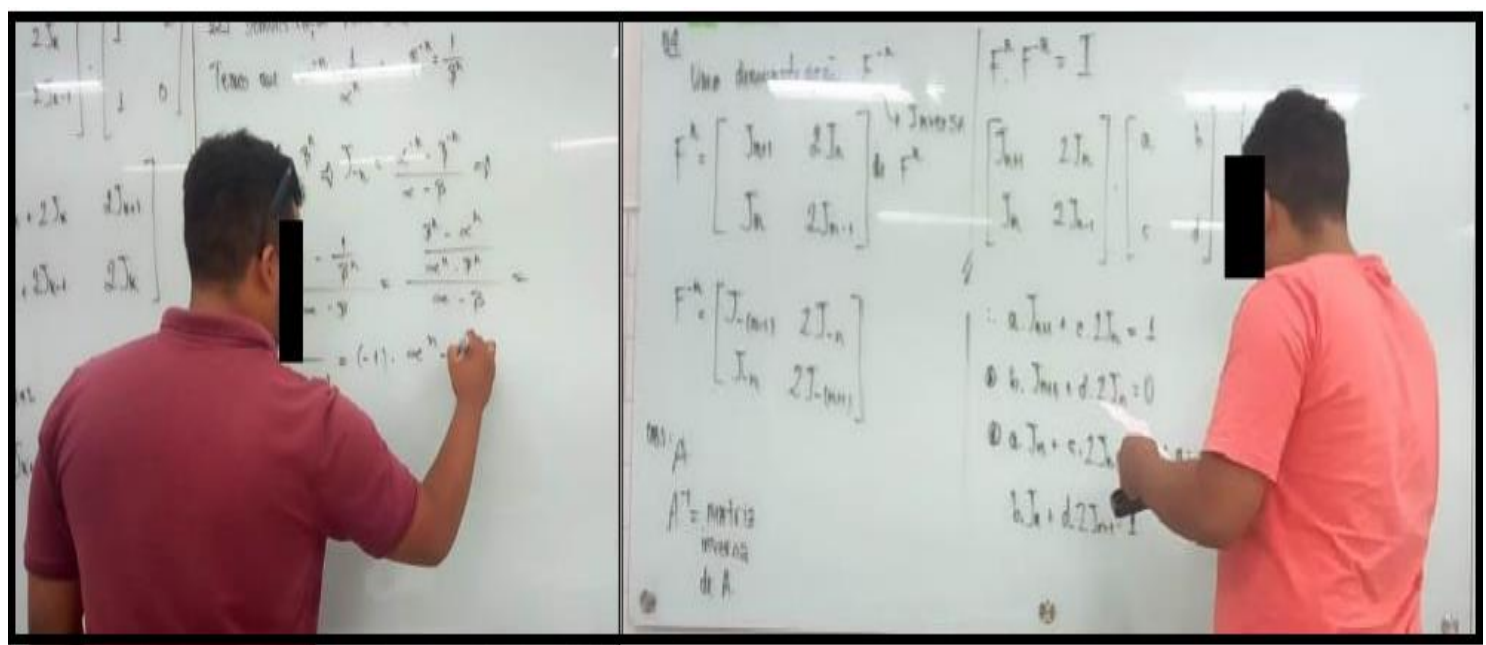

Figura 11. No estudo de Souza (2020) os professores desenvolveram e descobriram propriedades matriciais relacionadas com a Sequência de Jacobsthal

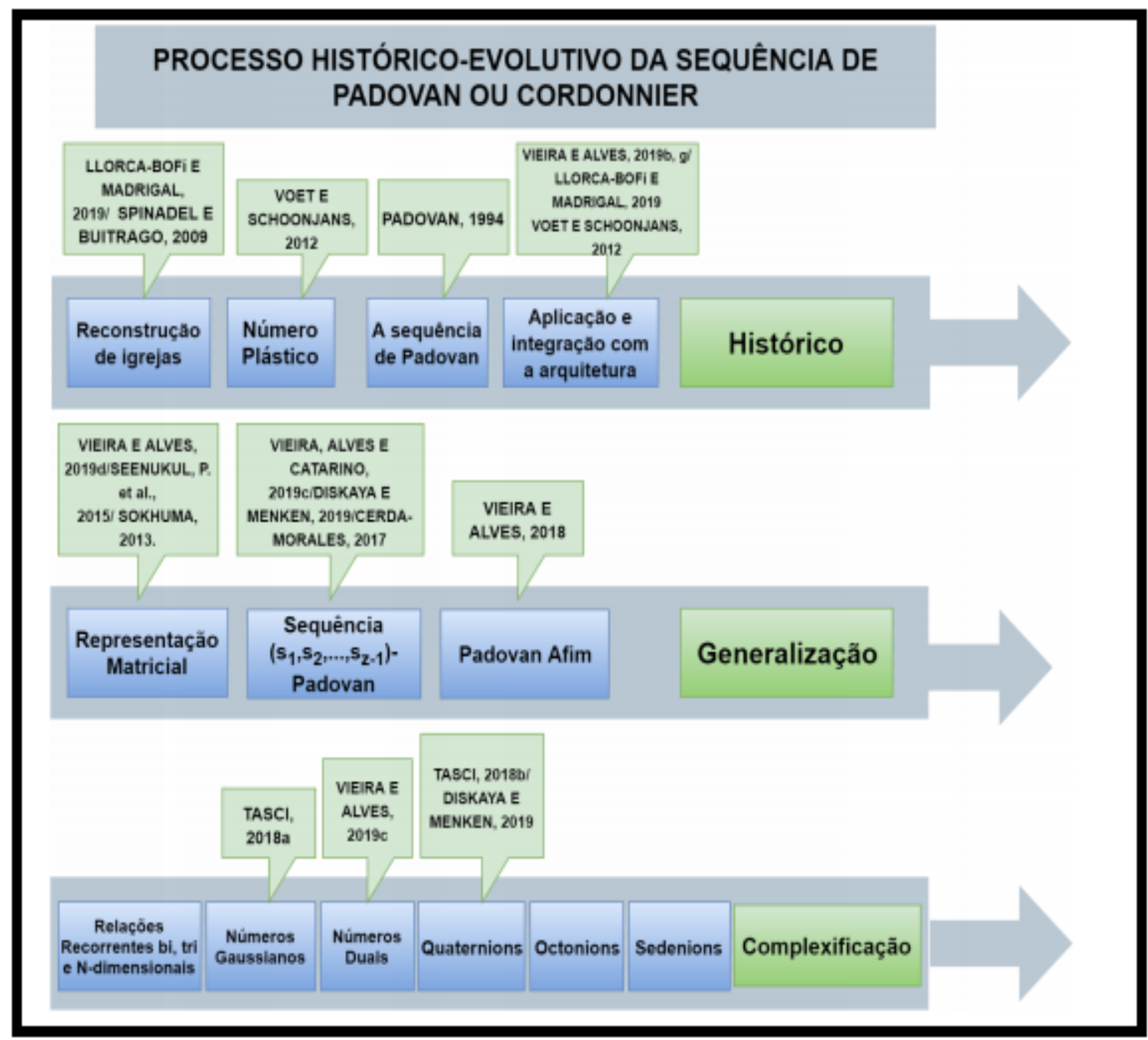

Figura 12. Vieira (2020) descreve um itinerário matemático e evolutivo relacionado com a sequência de Padovan ou de Coordonier 
Para concluir, na figura 12, visualizamos um fluxograma que revela um paulatino e dinâmico processo de contribuição e construção do saber científico e matemático em termos da sequência de Padovan, a sequencia correlata com a sequência de Fibonacci, todavia, desconsiderada pelos autores de compêndios de História da Matemática.

\section{Considerações finais e futuras investigações}

Nas seções predessoras apresentamos alguns dados e contribuições envolvendo uma amostra de trabalhos e dissertações de mestrado, cujas pesquisas desenvolvidas no Brasil, no contexto da formação inicial e continuada de professores, apresenta forte influência da pesquisa e das contribuições de matemáticos pesquisadores portugueses. (Vieira, Alves \& Machado, 2020).

Dessa forma, amparada nos pressupostos de uma Engenharia Didática de Formação e, mediante a concepção de situações didáticas (Brousseau, 1997), apresentamos alguns dados e exemplos obtidos por intermédio de um exame de trabalhos e projetos desenvolvidos no período de 2015 - 2020. Cabe assinar os projetos em desenvolvimento e que devem ser finalizados no período 2020 - 2022. Observamos as seguintes temáticas em desenvolvimento no Brasil: Engenharia Didática de Formação sobre a Sequência de Coordonier ou Padovan, Engenharia Didática de Formação sobre a noção de Números Figurais n-dimesionais e o processo de hibridização de sequências recorrentes (Barros et all, 2020; Ozdemir, 2018).

Observamos, por sua vez, que a noção de situação didática, na perpectiva de Brousseau (1997) possibilitou a concepção de um roteiro de intervenção, em sala de aula, e um exame da concepções dos professores, na medida em que, ocorriam as devidas interações com o material proposto para a investigação, tendo em vista a adoção da Teoria das Situações.

Como temos acentuados em nossos trabalhos, para a aquisição de um entendimento sobre o carater evolutivo e não estático do conhecimento matemático, os professores necessitam de exemplo, práticos, concretos e efetivos, que representam as ideias matemáticas desde sua etapa de gênese das definições e a constatação do interesse atual e a vigorosa pesquisa sobre o assunto. Sem tal recorte tanto no passado, bem como seu progresso atual, os professores adquirem uma visão estanque e apartada da Matemática, como um conjunto de episódios que ocorreram séculos e séculos atrás e adquirem um viés de curiosidade, em detrimento da aquisição de um robusto repertório de conhecimentos relacionados ao caráter histórico, epistemológico e, de modo inexorável, de caráter matemático (Alves \& Catarino, 2019). 


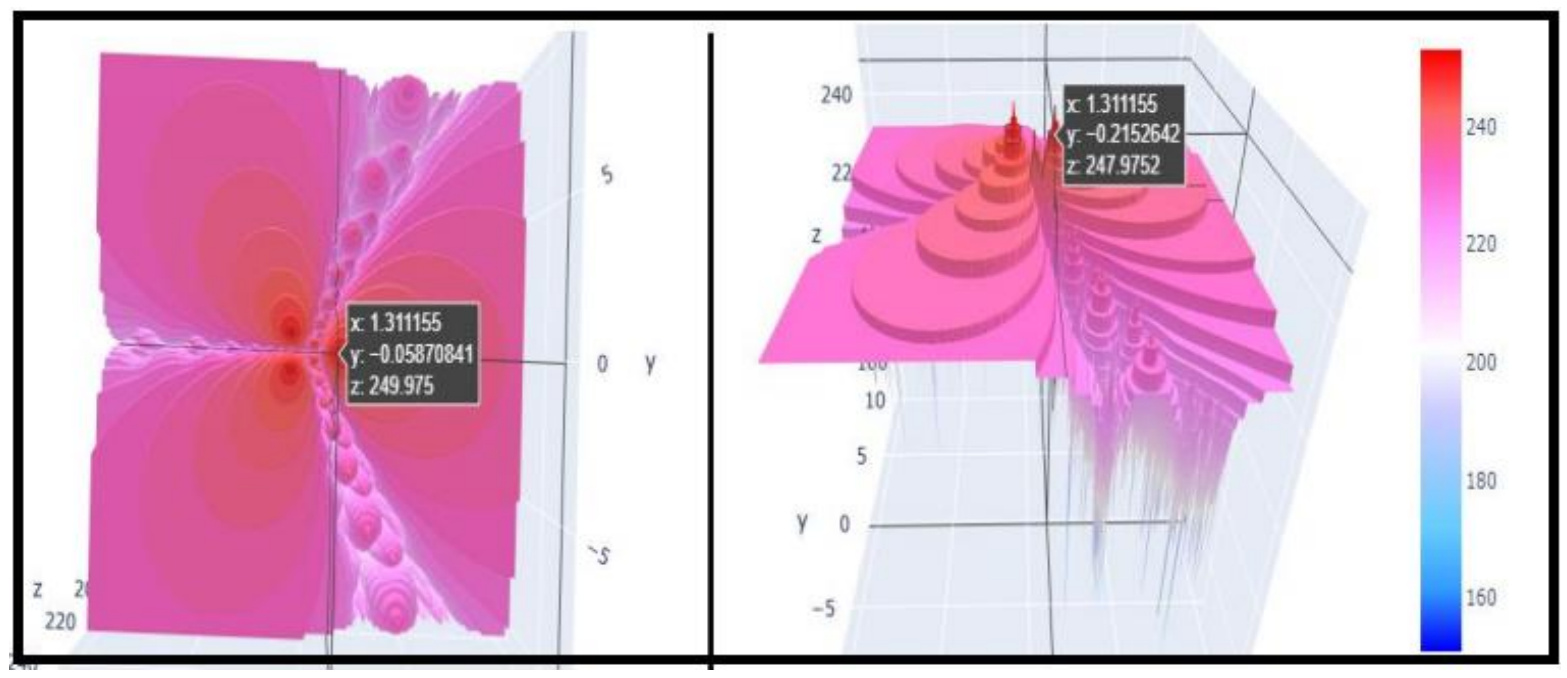

Figura 13. Alves, Catarino \& Vieira (2020) discutem representações computacionai 3D relacionadas com a sequência de Leonardo

No que concerne aos estudos futuros, a partir do acompanhamento da pesquisa em Matemática por parte dos pesquisadores portugueses, buscaremos identificar os vestígios de especialização e generalização de eventuais sequências numéricas não mencionadas no presente estudo, com eventual repercussão de abordagem tecnológica e representações computacionais (ver figura13). Ademais, tendo em vista da importância e um conhecimento aprofundado sobre a noção abstata de número e seu processo evolutivo (Alves \& Alves Dias, 2018), buscaremos descrever o processo de hibridização desssas sequências, com o uso da noção de número híbrido (Ozdemir, 2018).

\section{Referências}

Alves, F. R. V. \& Catarino, P. M. (2019). Situação Didática Profissional: um exemplo de aplicação da Didática Profissional para a pesquisa objetivando a atividade do professor de Matemática no Brasil, Indagatio Didactica, 11(1), 103 - 129.

Alves, F. R. V. (2017). Fórmula de de Moivre, ou de Binet ou de Lamé: demonstrações e generalidades sobre a sequência generalizada de Fibonacci - SGF. Revista Brasileira de História da Matemática, 17(1), 1-16.

Alves, F. R. V.; Catarino, P. M. M. C.; \& Mangueira, M. C. S. (2019). Discovering theorems about the gaussian mersenne sequence with the maple's help: implications for the mathematical theachers in brazil. Annals Computer Science Series, 17(1), 69 - 77.

Alves, F., R. V. \& Dias, M. A. (2018). An historical investigation about the dedekind's cuts: some implications for the teaching of mathematics in brazil, Acta Didactica Naposcencia, $11(3-4), 13-34$. 
Alves, F., R. V. (2018). The Quaterniontonic and Octoniontonic Fibonacci Cassini's Identity: An Historical Investigation with the Maple's Help. International Electronic Journal of Mathematics Education, 13(1), 1-14.

Alves, F., R. V. (2019a). Sequência de Oresme e algumas propriedades (matriciais) generalizadas. Revista eletrônica paulista de matemática, 16(1), 28-52.

Alves, F., R. V. (2019b). Brahmagupta e alguns elementos históricos da matemática hindu, Revista Thema, 16(4), 755 - 763.

Alves, F., R. V.; Vieira, R. P. M. (2020). The Newton Fractal?s Leonardo Sequence Study with the Google Colab. International Electronic Journal of Mathematics Education, 15(1), 111 .

Alves, F. R. V. \& Vieira, R. P. M. (2020). The Newton Fractal's Leonardo Sequence Study with the Google Colab. International Electronic Journal of Mathematics Education, 15(2), 19

Artigue, M. (1988). Ingénierie didactique, Recherches en Didactique des Mathématiques, 9(3), 281-308.

Artigue, M. (1990). Épistémologie et didactique. Recherches en didactique des mathématiques, 10(2.3), 241-285.

Artigue, M. (1991). Ingénierie Didactique en Mathématiques, Didactique des Mathématiques, 2(1), $1-22$.

Artigue, M. (2002). Ingénierie didactique : quel rôle dans la recherche didactique aujourd'hui ? Les Dossiers des Sciences de l'Education, 8(1), 59 - 72.

Barros, E. et all. (2020). Hibridização dos números triangulares: uma análise preliminar e a priori e a visualização por meio do software GeoGebra, Revista Indagatio Didactica, $12(3), 411-435$.

Barquero, B; \& Bosch, M. (2015). Didactic Engineering as a Research Methodology: From Fundamental Situations to Study and Research Paths. In: Watson, A.; Ohtani, Minoru. Task Design In Mathematics Education. ICMI study 22, New York: Springer, 251 - 270.

Brousseau, G. (1997). Theory of didactical situations in mathematics. Dordrecht, The Netherlands: Kluwer

Campos, H.; Catarino, P. M.; Aires, A. P, Vasco, P. \& Borges, A. (2014). On Some Identities of k-Jacobsthal-Lucas Numbers, 8(10), 489 - 494.

Catarino, P. M. C. \& Borges, A. (2020). On Leonardo Numbers, Acta Mathematica Universitatis Comenianae, 89(1), $71-86$.

Catarino, P. M. C. (2016). The modified Pell and the Modified k-Pell Quaternions and Octonions, Advances in Applied Clifford Algebra, 26(2), 577 - 590.

Catarino, P. M. C. (2019). On k-Pell hybrid numbers, Journal of Discrete Mathematical Sciences and Cryptography, 22(1), 83 - 89.

Catarino, P. M. C.; \& Vasco, P. (2013). On Some Identities and Generating Functions for kPell-Lucas Sequence, Applied Mathematical Sciences, 7(98), 4867 - 4873. 
Catarino, P. M. C.; \& Vasco, P. (2017). On dual k-Pell quaternions and octonions, Mediterranean Journal of Mathematics, 14(75), 1 - 20.

Catarino, P. M.; Campos, H.; \& Vasco, P. J. (2019). A note on k-Pell, k-Pell-Lucas and Modified k-Pell numbers with arithmetic indexes, Acta Mathematica Universitatis Comenianae, 89(1), $97-107$.

Cook, C. (2004). Some sums related to sums of Oresme numbers. In: Howard, F. T. Application of Fibonacci numbers. Dordrecht: Springer, 87 - 101.

Dos Santos, A. A. (2017). Uma Engenharia Didática para a noção de sequência extendida de Fibonacci: uma experiência no contexto do IFCE (dissertação de mestrado), Fortaleza: Instituto Federal de Educação Ciência e Tecnologia do Estado do Ceará, Brasil.

Gould, H. W. (1981). A history of the fibonacci q-matrix and a higher-dimensional problem, The Fibonacci Quarterlly, 19(3), 250 - 257.

Guedes, A. M. (2020). Uma Engenharia Didática para o estudo da Sequência Generalizada de Lucas (SGL) (dissertação de mestrado), Fortaleza: Instituto Federal de Educação Ciência e Tecnologia do Estado do Ceará, Brasil.

Harman, C. H. (1981). Complex Fibonaci Numebrs, The Fibonacci Quarterly, 19(1), 82 - 87.

Iver, M. (1961). Some Results on Fibonacci Quaternions, The Fibonacci Quarterly, 7(2), 201 211.

Mangiante-Orsola, C. \& Perrin-Glorian, M. J. (2016). Ingenierie didactique de developpement en geometrie au cycle 3 dans le cadre du lea valenciennes-denain, Actes du séminaire national de l'ARDM, 35 - 59.

Oliveira, R. R. (2018). Engenharia Didática com o tema: relações bidimensionais, tridimensionais e n-dimensionais do modelo de Fibonacci (dissertação de mestrado), Fortaleza: Instituto Federal de Educação Ciência e Tecnologia do Estado do Ceará, Brasil.

Oliveira, R. R.; \& Alves, F. R. V. (2019). An investigation of the Bivariate Complex Fibonacci Polynomials supported in Didactic Engineering: an application of Theory of Didactics Situations (TSD). Revista Acta Scientiae, 21(2), 170-195.

Ozdemir, M. (2018). Introduction to Hybrid Numbers", Adv. Appl. Cliford Algebras, 28(11), 1 -40 .

Perrin-Glorian, M. J. \& Bellemain, P. M. (2019). L'ingenierie didactique entre recherche et ressource pour l'enseignement et la formation des maitres, Caminhos da Educação Matemática em Revista/Online, 9(1), 45 - 82.

Perrin-Glorian, M. J. (2011). L'ingénierie didactique à l'interface de la recherche avec l'enseignement. Développement de ressources et formation des enseignants. In Margolinas C.et al. (Eds.) En amont et en aval des ingénieries didactiques. Grenoble: La Pensée Sauvage.

Perrin-Glorian, M. J. (2019). A l'interface entre recherche et enseignement, les ingénieries didactiques, ler Congrès international de la Théorie de l'Action Conjointe en Didactique, $1-13$. 
Shannon, A.G., Anderson, P.G. \& Horadam, A.F. (2006). Properties of Cordonnier, Perrin and Van der Laan Numbers. International Journal of Mathematical Education in Science and Technology, 37(7), 825-831.

Singh, P. (1985). The So-called Fibonacci Numbers in Ancient and Medieval India, Historia Mathematica, 12(1), 229 - 244.

Sridharan, R. ; Sridharan; R. \& Srinivas, M. (2015). Nārāyaa’s Generalisation of Mātrāvottaprastāra and the Generalised Virahāka-Fibonacci Representation of Numbers, Indian Journal of History of Science, 50(2), 227 - 244.

Stakov, A. (2009). The Mathematics of Harmony: from Euclid to contemporary mathematics and computer science, London: Word Scientific Press.

Tempier, F. (2016). New perspectives for didactical engineering: an example for the development of a resource for teaching decimal number system, Journal of Mathematics Teacher Education, 19( 2 - 3), 261 - 276.

Tempier, F.; \& Chambris, C. (2017). Concevoie une ressource pour l'enseignment de la numération décimale de position, Recherche En Didactique des Mathématiques, 37(2 3), $289-332$.

Vieira, R. P. M.; \& Alves, F. R. V. (2019b). Sequences of Tridovan and their identities. Notes on number theory and discrete mathematics, 25(1), 185-197.

Vieira, R. P. M.; Alves, F., R. V.; \& Catarino, P. M. C. (2019). O estudo da Sequência de Padovan aplicado à Engenharia Didática: uma experiência no curso de Licenciatura em Matemática. Indagatio Didactica, 14(1), 260 - 279.

Vieira, R. P. M.; Alves, F., R. V.; \& Catarino, P. M. C. (2020). Padovan sequence generalization - a study of matrix and generating function, Notes in Number Theory and Discrete Mathematics, 26(4), $1-12$.

Vieira, R. P. M; \& Alves, F., R. V. (2019a). Propriedades das extensões da Sequência de Padovan. Revista eletrônica paulista de matemática, 15(1), 24-40.

Vieira, R. P. M. (2020). Engenharia Didática (ED): o caso da Generalização e complexificação da sequência de Coordonier ou Padovan. (dissertação de mestrado). Fortaleza: Instituto Federal de Educação, Ciências e Tecnologia do Estado do Ceará.

Yilmaz, N. \& Taskara. N. (2013). Matrix Sequences in terms of Padovan and Perrin Numbers, Journal of Applied Mathematics, 13(10), 1 - 12.

Autores:

Francisco Regis Vieira Alves. Professor Titular do Instituto Federal de Educação, Ciência e Tecnologia do Estado do Ceará - IFCE, departamento de Matemática e Física. Bolsista de Produtividade em Pesquisa do Conselho Nacional de Desenvolvimento Científico e Tecnológico - CNPQ/PQ2. Docente Permanente do Mestrado Acadêmico em Ensino de Ciências e Matemática - PGECM/IFCE. Docente Permanente do Mestrado Profissional em Educação Profissional e Tecnológica PROEPT/IFCE em Rede. Docente Permanente do Doutorado em Rede Região Nordeste - RENOEN. Brasil 
Paula Maria Machado Cruz Catarino. https://orcid.org/0000-0001-6917-5093. Hold a $\mathrm{PhD}$ in Mathematics. Associate Professor of UTAD (Universidade de Trás-os-Montes e Alto Douro). Researcher of Research Centre CMAT-UTAD- Polo of CMAT of University of Minho and also Researcher of the Research Centre CIDTFF - Research Centre "Didactics and Technology in Education of Trainers. Currently Vice-President of Scientific Council. Author of papers in international scientific journals with peer review. Portugal 